\title{
Spinal Cord Motion: Influence of Respiration and Cardiac Cycle
}

\section{Rückenmarksbewegungen: Bestimmung des Einflusses von Atmung und Herzzyklus mittels MRT}

Authors

Affiliations
S. Winklhofer ${ }^{1,2}$, F. Schoth ${ }^{3}$, P. Stolzmann ${ }^{2}$, T. Krings ${ }^{4}$, M. Mull' , M. Wiesmann ${ }^{1}$, C. P. Stracke ${ }^{1,5}$

Department of Neuroradiology, RWTH Aachen University Hospital, Aachen, Germany

Institute of Diagnostic and Interventional Radiology, University Hospital Zurich, Switzerland

Department of Diagnostic Radiology, RWTH Aachen University Hospital, Germany

4 Division of Neuroradiology, Department of Medical Imaging, Toronto Western Hospital, UHN, Toronto, Ontario, Canada

Department of Neuroradiology, Alfried-Krupp-Hospital, Essen, Germany
Key words

- spinal cord

- MR imaging

- CNS received $\quad 18.1 .2014$

accepted 21.3.2014

\section{Bibliography}

DOI http://dx.doi.org/ 10.1055/s-0034-1366429

Published online: 22.4 .2014

Fortschr Röntgenstr 2014; 186: 1016-1021 @ Georg Thieme Verlag KG Stuttgart · New York . ISSN 1438-9029

\section{Correspondence}

Dr. Sebastian Winklhofer Institute of Diagnostic and Interventional Radiology, University Hospital Zurich Raemistr. 100

8091 Zurich

Switzerland

Tel.: ++ 41/44/2551111

Fax: ++41/44/2554443

sebastian.winklhofer@usz.ch

\section{Zusammenfassung}

$\nabla$

Ziel: Ziel der Studie war es, mittels MRT (Magnetresonanztomografie), den Einfluss des Herzzyklus auf die physiologische Rückenmarksbewegung mit dem Einfluss der Atmung zu vergleichen.

Material und Methoden: Bei 16 gesunden, freiwilligen Probanden (Altersemedian 25 Jahre) wurden Rückenmarksbewegungen innerhalb des Spinalkanals mittels Herz-getriggerten und EKG-synchronisierten Gradienten Echo-Puls MRT-Sequenzen untersucht. Die Aufnahmen wurden während Atemanhalten, normalem Atmen und kräftigem Atmen durchgeführt. Normwerte für die Rückenmarksbewegung wurden mittels deskriptiver Statistik berechnet. Atemabhängige Unterschiede wurden mittels des Wilcoxon-Vorzeichen-RangTestes ermittelt und mit der Herzzyklus-bedingten Rückenmarksbewegung verglichen.

Ergebnisse: Eine Normwerttabelle für zervikale, thorakale und lumbale Rückenmarksbewegungen auf Höhe eines jeden Wirbelsegmentes wurde erstellt. Signifikante Unterschiede im Ausmaß der Rückenmarksbewegung zeigten sich zwischen den Untersuchungen während des Atemstillstandes (Herzzyklus-bedingten Bewegung) und den beiden atemabhängigen Aufnahmen (jeweils $\mathrm{p}<0,01$ ). Die größten Rückenmarksbewegungen wurden während kräftigem Atmen detektiert, mit Höchstwerten auf Höhe der unteren Zervikalsegmente (C5; Mittelwert 2,1 $\mathrm{mm} \pm 1,17$ ). Die Aufnahmen während Atemanhalten ergaben die niedrigsten Werte an Rückenmarksbewegung.

Schlussfolgerung: MRT erlaubt die Darstellung und Beurteilung von herzzyklus-, und atemabhängigen Rückenmarksbewegungen innerhalb des Spinalkanals von zervikalen bis lumbalen Wirbelsegmenten. Atembedingte Einflüsse haben, im Vergleich zu herzzyklus-bedingten Einflüssen, hierbei scheinbar eine deutlich größere Auswirkung auf die Rückenmarksbewegung.

\section{Abstract \\ $\nabla$}

Purpose: To assess physiological spinal cord motion during the cardiac cycle compared with the influence of respiration based on magnetic resonance imaging (MRI) measurements.

Materials and Methods: Anterior-posterior spinal cord motion within the spinal canal was assessed in 16 healthy volunteers (median age, 25 years) by cardiac-triggered and cardiac-gated gradient echo pulse sequence MRI. Image acquisition was performed during breath-holding, normal breathing, and forced breathing. Normal spinal cord motion values were computed using descriptive statistics. Breathing-dependent differences were assessed using the Wilcoxon signed-rank test and compared with the cardiac-based cord motion.

Results: A normal value table was set up for the spinal cord motion of each vertebral cervicothoracic-lumbar segment. Significant differences in cord motion were found between cardiacbased motion while breath-holding and the two breathing modalities $(\mathrm{P}<0.01$ each). Spinal cord motion was found to be highest during forced breathing, with a maximum in the lower cervical spinal segments (C5; mean, $2.1 \mathrm{~mm} \pm 1.17$ ). Image acquisition during breath-holding revealed the lowest motion.

Conclusion: MRI permits the demonstration and evaluation of cardiac and respiration-dependent spinal cord motion within the spinal canal from the cervical to lumbar segments. Breathing conditions have a considerably greater impact than cardiac activity on spinal cord motion.

Key points:

- Cardiac-triggered and ECG-gated MRI allows for demonstration of the smallest spinal cord motions.

- Respiratory influences seem to have the highest impact on spine motion. 
Kernaussagen:

- MRT mit Herz-getriggerten und EKG-synchronisierten EchoPuls-Sequenzen ermöglicht die Darstellung kleinster Rückenmarksbewegungen.

- Atemabhängige Einflüsse scheinen die größte Auswirkung auf den Bewegungsumfang zu haben.

- Der Einfluss des Herzzyklus auf die Rückenmarksbewegungen scheint dagegen gering zu sein.

- Die geringsten Rückenmarksbewegungen wurden bei Atemanhalten registriert.
- In contrast, the influence of the cardiac cycle seems to be small.

- The smallest spinal cord motions were measured during breath-hold.

Citation Format:

- Winklhofer S, Schoth F, Stolzmann P et al. Spinal Cord Motion: Influence of Respiration and Cardiac Cycle. Fortschr Röntgenstr 2014; 186: 1016-1021

\section{Introduction}

\section{$\nabla$}

Magnetic resonance imaging (MRI) is considered to be the standard reference modality for spinal cord imaging. Pathologies such as myelopathy, spinal cord tumors, or demyelinating lesions can be visualized at a higher sensitivity and specificity compared with other imaging modalities such as ultrasonography and computed tomography $[1,2]$. New techniques such as spinal functional-MRI (fMRI), diffusion tensor imaging (DTI), or spectroscopy permit more detailed and specific assessments of the normal anatomy, physiological changes, and pathologic lesions [3 - 5]. The spinal cord shows physiological motion within the spinal canal in all three directions, which has been investigated in several previously published studies [6-8]. It is known that next to the venous plexus, the surrounding cardiac-pulsation-related cerebrospinal fluid (CSF) is responsible for periodic spinal cord motion within the spinal canal [9-12]. This spinal cord motion and pulsation artifacts result in a reduced morphological assessment as well as limitations in motion-sensitive MR sequences, such as those used for fMRI or DTI [13 - 15]. Therefore, several studies attempted to demonstrate the possibility of reducing such artifacts using techniques such as cardiac gating or respiration triggering $[16,17]$.

The literature describes the greatest direction of myelon motion as anterior-posterior (AP) $[8,18]$, while most studies examine cranio-caudal motion $[8,19-21]$. However, none of these studies compared the influence of respiration with physiologic spinal cord motion induced by heart activity. Until now, this had not been sufficiently shown by MRI on segmental levels.

Cine-sequence MRI, a common and established cardiac imaging technique $[22,23]$ based on a prospective ECG-triggered k-space segmentation, is applicable to demonstrate cardiac cycle-dependent spinal cord motion [19].

This study was designed to assess the range of physiological spinal cord motion and the influence of respiration in comparison with the physiological influence of heart activity on spinal cord motion at each segmental level within the cervico-thoracic-lumbar spinal canal based on MRI measurements.

\section{Materials and Methods}

$\nabla$

\section{Volunteers}

MRI was performed in 16 healthy volunteers ( 6 women, 10 men; median age, 25 years; range, 20 - 33 years; median BMI, 23.8). None of the volunteers suffered from anamnestic neurological or orthopedic disease, and all claimed to be in a state of good health. The exclusion criteria were age $<18$ years, a history of back pain, a history of spinal surgery or known spinal disease, and general MRI-related exclusion criteria such as metallic implants, foreign bodies, or claustrophobia. None of the volunteers who participated after a public request on the universities notice board had to be excluded due to one of those exclusion criteria. Therefore, there was no influence for the age or sex distribution.

The study was conducted according to the Declaration of Helsinki and in accordance with the ethical standards on human experimentation at our institute. Informed consent was obtained from all volunteers.

\section{Imaging and Measurements}

Data acquisition was performed using a 1.5-T full-body MRI system (Philips Achieva; Philips Medical Systems, Best, Netherlands). All images were acquired using a spine coil with volunteers placed in the supine position. Initially, sagittal T1-and T2-weighted ( $\mathrm{w}$ ) images were performed to exclude pathologic findings, such as degenerative changes or spinal canal stenosis, followed by gradient echo sequences to assess spinal cord motion. The latter were performed with three different breathing techniques: first, during a 30-s breath-hold (to assess only heart activity influences); second, with normal regular breathing; and finally, during forced breathing. All volunteers were thoroughly instructed in the commands during an earlier practice runthrough outside the scanner where all procedures were repeated several times.

Normal regular breathing was instructed as a mixture of the abdominal and thoracic quiet breathing type without using the inspiratory or expiratory reserve volume of the lungs [24, 25]. The volume of air breathed in and out at rest equates to the tidal volume and is approximately $0.5 \mathrm{l}$ in an average, healthy adult [26]. Forced breathing was defined and instructed to the volunteers as a mixture of the abdominal and thoracic breathing type with use of the inspiratory reserve volume (maximal inspiration) or expiratory reserve volume (maximal expiration) of the lungs $[24,25]$. This breathing maneuver results in an in/expired air volume of approximately $2.4-3.8 \mathrm{l}$, equating the inspiratory capacity [26].

To avoid intrathoracic pressure changes and arterial as well as venous velocity changes with the physiological decrease of the heartbeat and during breath-hold, volunteers were introduced to perform breath-holding in expiration resembling small lung volume breath-hold [27, 28].

The scan protocol used in this study included an initial mid-sagittal T1-w turbo spin echo (TSE) sequence (echo time (TE): 7.40 $\mathrm{ms}$; repetition time (TR): $400 \mathrm{~ms}$; matrix size: $256 \times 256$; inplane resolution $0.97 \times 0.97 \mathrm{~mm}$; slice thickness: $5 \mathrm{~mm}$; intersection gap: $1 \mathrm{~mm}$; flip angle: $90^{\circ}$; field of view (FOV): $250 \mathrm{~mm}$ ), a sagittal T2-w sequence (TE: 112 ms; TR: 3160 ms; matrix size: $256 \times 256$; slice thickness: $4 \mathrm{~mm}$; intersection gap: $4 \mathrm{~mm}$; field of view (FOV): $240 \mathrm{~mm}$ ), a sagittal T1-W single-slice gradient echo (GRE) sequence for respiratory-dependent image acquisi- 
tion (TE: $2.10 \mathrm{~ms}$; TR: $4.1 \mathrm{~ms}$; matrix size: $256 \times 256$; in-plane resolution $0.97 \times 0.97 \mathrm{~mm}$; slice thickness: $4 \mathrm{~mm}$; flip angle: $50^{\circ}$; FOV: $250 \mathrm{~mm}$; and cardiac synchronization with ECG-cardiac triggering with single heart phases and longest trigger delay). In addition, a sagittal T1-w GRE sequence was performed for respiratory-dependent image acquisition during breath-holding (TE: $1.95 \mathrm{~ms}$; TR: $4.0 \mathrm{~ms}$; matrix: $256 \times 256$; in-plane resolution $0.97 \times 0.97 \mathrm{~mm}$; slice thickness: $4 \mathrm{~mm}$; intersection gap: $2 \mathrm{~mm}$; flip angle: $65^{\circ}$; FOV: $250 \mathrm{~mm}$; and cardiac synchronization with ECG-cardiac gating with 15 heart phases and shortest gate delay in breath expiration). Those cine images required the volunteers to hold their breath for approximately $30 \mathrm{~s}$, which had been tested during the practice run and was feasible for all participating volunteers without any problems.

A short time interval was taken after each breathing technique of approximately two minutes to avoid physiological stress to the participants and to give voice prompts to the volunteers about the beginning of the next scan.

The obtained images permitted cinematic spinal cord motion analysis by lacing the images together.

The total duration of this examination was $<20 \mathrm{~min}$.

\section{Data Analysis}

Measurements were performed by two radiologists on the MR console (Advance Viewer; Philips Medical Systems, Best, Netherlands) in consensus (SW and CS, blinded for review). The reviewers had 1 and 7 years of experience in spinal radiology.

A horizontal line, perpendicular to the vertebral body long axis in the sagittal T1-w image and at right angles to the anterior cord surface at each level ( $\bullet$ Fig. 1 ), was drawn using the electronic caliper tool provided by the MR console software. The location for this line in the $\mathrm{x}$-axis was defined as the middle of the vertebral body. This was repeated for all levels, starting with the second cervical and ending with the second lumbar vertebral body. A one-dimensional histogram was calculated by the vendor's application software.

Mathematical oversampling was used with a self-developed spline interpolation algorithm to increase the achieved low resolution. Therefore, a Canny-algorithm, which has been frequently used and established in vascular imaging, was applied to permit myelon definition toward the surrounding CSF and motion detection in a submillimeter range [29].

Using spline interpolation, the spatial resolution of the one-dimensional histograms was increased by a factor of 10 . At each vertebral level the (temporal) first histogram served as the stand-



Fig. 1 Sagittal gradient echo magnetic resonance image (MRI) of the cervico-thoracic junction. Measurement lines were placed on each segmental level.

Abb. 1 Sagittales Gradienten-Echo MRT des zerviko-thorakalen Übergangs. Die Messlinien wurdenauf jeweiliger segmentaler Höhe platziert. ard with a displacement of zero. All (temporal) following histograms were correlated to that first histogram. For this (one dimensional) voxel-wise displacements along the axis of the histogram data were tested. The displaced (temporal) following histograms were then correlated to the (temporal) first histogram. The maximal Pearson's correlation coefficient indicated the displacement of the (temporal) following histogram. Therefore, the displacement was a discrete value with a spatial resolution of $1 / 10$ of the imaging voxel size. This technique allowed for measurements of the spinal cord motion independent from the physiological movement of the body while breathing.

The offset was calculated to show the highest correlation to the initial profile. This corresponded to the AP motion, measured in $\mathrm{mm}$.

\section{Statistical Analysis}

Continuous variables were expressed as means \pm standard deviations, and categorical variables as frequencies and percentages. Because the results of the Kolmogorov-Smirnov test and the visual inspection showed non-normally distributed data, the Wilcoxon signed-rank test was used to determine the significance between the breathing groups. Furthermore, the Wilcoxon signed-rank test was used to determine significance between cervical, thoracic, and lumbar motion and the three breathing types. A P-value $<0.05$ was considered statistically significant.

Statistical analysis was performed using the IBM SPSS statistics software (release 20.0; SPSS Inc., Chicago, IL, USA).

\section{Results}

$\nabla$

The median weight and median body size were validated as normal according to the German population [30].

- Table 1 demonstrates the mean \pm standard deviation and the minimum and maximum results of spinal cord motion in the AP direction within the spinal canal, measured in $\mathrm{mm}$, with respect to the acquisitions during breath-holding, normal breathing, and forced breathing.

The mean maximum AP motion measurements differed significantly between the breath-holding, normal breathing, and forced breathing tests $(\mathrm{P}<0.01$ each).

The highest mean values for all levels were found in the forced breathing group (mean $1.32 \mathrm{~mm} \pm 0.38$; range, $0.76-2.1 \mathrm{~mm}$ ). The spinal motion values during breath-holding and normal breathing (mean $0.19 \mathrm{~mm} \pm 0.04$, range $0.14-0.29 \mathrm{~mm}$; and mean $0.31 \mathrm{~mm} \pm 0.09$, range $0.21-0.46 \mathrm{~mm}$, respectively) were significantly lower than those during forced breathing. Finally, the mean values for spinal cord motion during breath-holding were significantly lower than those during normal breathing measurements $(\mathrm{P}<0.01)$.

Among all three conditions, the AP spinal cord motion values differed significantly between the grouped test pairs in the cervical, thoracic, and lumbar regions ( $\mathrm{P}<0.01$ each). The corresponding spinal cord motion results with regard to the different vertebral column regions are shown in $\bullet$ Table 2.

The highest mean AP spinal cord motion values occurred during forced breathing on levels C4 and C5 in the lower cervical spinal segment (1.98 and $2.1 \mathrm{~mm}$, respectively).

Spinal cord motion during breath-holding was highest at the levels of the first and second thoracic vertebral bodies (means, $0.29 \mathrm{~mm}$ and $0.28 \mathrm{~mm}$, respectively). 
Table 1 Measured spinal cord motion values $(\mathrm{mm})$ in the AP direction of the vertebral column for each level with respect to the different breathing modalities used during data acquisition.

Tab. 1 Ausmaß der ermittelten Rückenmarksbewegungen $(\mathrm{mm})$ in AP-Richtung für die untersuchten Wirbelkörperhöhen in Abhängigkeit der unterschiedlichen Atemtechniken.

\begin{tabular}{|llllllllllllllllllllll} 
level & C2 & C3 & C4 & C5 & C6 & C7 & T1 & T2 & T3 & T4 & T5 & T6 & T7 & T8 & T9 & T10 & T11 & T12 & L1 & L2 \\
\hline breath-hold & & & & & & & & & & & & & & & & & & \\
\hline mean & 0.19 & 0.18 & 0.21 & 0.19 & 0.19 & 0.21 & 0.29 & 0.28 & 0.20 & 0.17 & 0.17 & 0.19 & 0.14 & 0.15 & 0.16 & 0.15 & 0.14 & 0.18 & 0.19 & 0.17 \\
\hline SD & 0.04 & 0.06 & 0.09 & 0.12 & 0.12 & 0.10 & 0.13 & 0.20 & 0.13 & 0.08 & 0.05 & 0.10 & 0.09 & 0.07 & 0.09 & 0.09 & 0.05 & 0.08 & 0.10 & 0.06 \\
\hline minimum & 0.1 & 0.1 & 0.1 & 0.1 & 0 & 0.1 & 0.1 & 0.1 & 0.1 & 0.1 & 0.1 & 0.1 & 0 & 0.1 & 0.1 & 0 & 0.1 & 0.1 & 0.1 & 0.1 \\
\hline maximum & 0.3 & 0.3 & 0.5 & 0.6 & 0.5 & 0.1 & 0.6 & 1.0 & 0.5 & 0.4 & 0.2 & 0.4 & 0.3 & 0.3 & 0.4 & 0.3 & 0.2 & 0.3 & 0.3 & 0.2 \\
\hline normal breathing & & & & & & & & & & & & & & & & & & & & \\
\hline mean & 0.29 & 0.41 & 0.46 & 0.43 & 0.39 & 0.38 & 0.46 & 0.33 & 0.34 & 0.32 & 0.25 & 0.21 & 0.21 & 0.22 & 0.21 & 0.23 & 0.24 & 0.29 & 0.37 & 0.23 \\
\hline SD & 0.24 & 0.39 & 0.39 & 0.33 & 0.27 & 0.20 & 0.27 & 0.17 & 0.19 & 0.16 & 0.11 & 0.11 & 0.11 & 0.12 & 0.11 & 0.13 & 0.13 & 0.14 & 0.14 & 0.06 \\
\hline minimum & 0.1 & 0.1 & 0.1 & 0.2 & 0.1 & 0.2 & 0.2 & 0.1 & 0.1 & 0.1 & 0.1 & 0.1 & 0.1 & 0.1 & 0.1 & 0.1 & 0.1 & 0.1 & 0.2 & 0.2 \\
\hline maximum & 1.1 & 1.7 & 1.7 & 1.4 & 1.0 & 0.8 & 1.2 & 0.7 & 0.8 & 0.7 & 0.5 & 0.5 & 0.5 & 0.5 & 0.4 & 0.5 & 0.5 & 0.5 & 0.6 & 0.3 \\
\hline forced breathing & & & & & & & & & & & & & & & & & & \\
\hline mean & 1.16 & 1.59 & 1.98 & 2.10 & 1.82 & 1.49 & 1.46 & 1.36 & 1.41 & 1.36 & 1.04 & 0.85 & 0.76 & 0.94 & 1.02 & 1.06 & 1.19 & 1.44 & 1.49 & 0.80 \\
\hline SD & 0.62 & 0.84 & 1.00 & 1.17 & 1.07 & 0.88 & 0.75 & 0.64 & 0.67 & 0.63 & 0.23 & 0.35 & 0.41 & 0.46 & 0.45 & 0.53 & 0.63 & 0.75 & 0.69 & 0.14 \\
\hline minimum & 0.3 & 0.4 & 0.5 & 0.4 & 0.5 & 0.5 & 0.5 & 0.5 & 0.6 & 0.5 & 0.7 & 0.4 & 0.3 & 0.3 & 0.4 & 0.3 & 0.2 & 0.3 & 0.4 & 0.7 \\
\hline maximum & 2.7 & 3.5 & 4.2 & 4.9 & 4.8 & 3.7 & 2.6 & 2.2 & 2.6 & 3.0 & 1.5 & 1.6 & 1.6 & 1.8 & 1.8 & 2.1 & 2.4 & 2.8 & 2.7 & 0.9 \\
\hline
\end{tabular}

Table 2 Measured spinal cord motion values $(\mathrm{mm})$ in the AP direction of the vertebral column in different regions with respect to the different breathing modalities used during data acquisition.

Tab. 2 Ausmaß der ermittelten Rückenmarksbewegungen ( $\mathrm{mm}$ ) in APRichtung für die untersuchten Wirbelsäulenabschnitte in Abhängigkeit der unterschiedlichen Atemtechniken.

\begin{tabular}{|c|c|c|c|}
\hline region & cervical & thoracic & lumbar \\
\hline \multicolumn{4}{|l|}{ breath-hold } \\
\hline mean & 0.20 & 0.18 & 0.19 \\
\hline SD & 0.09 & 0.11 & 0.09 \\
\hline minimum & 0.0 & 0.05 & 0.1 \\
\hline maximum & 0.6 & 1.0 & 0.3 \\
\hline \multicolumn{4}{|c|}{ normal breathing } \\
\hline mean & 0.39 & 0.27 & 0.34 \\
\hline SD & 0.31 & 0.16 & 0.13 \\
\hline minimum & 0.1 & 0.06 & 0.2 \\
\hline maximum & 1.7 & 1.2 & 0.6 \\
\hline \multicolumn{4}{|c|}{ moderate forced breathing } \\
\hline mean & 1.59 & 1.11 & 1.40 \\
\hline SD & 1.02 & 0.62 & 0.68 \\
\hline minimum & 0 & 0.05 & 0.4 \\
\hline maximum & 4.9 & 3.0 & 2.7 \\
\hline
\end{tabular}

The greatest motion during normal breathing was detected on levels C4 and T1 (mean, $0.46 \mathrm{~mm}$ each), with a second peak in the lumbar region (level L1; mean, $0.37 \mathrm{~mm}$ ).

The lowest mean spinal cord motion was detected during breathholding on all examined levels compared with data acquired during normal or forced breathing.

- Fig. 2 shows the mean values of AP spinal cord measurements on each vertebral level with respect to the different breathing types.

\section{Discussion}

In this study, we investigated the influence of respiration on spinal cord motion compared with physiological motion induced by cardiac cycle caused by heart activity. Furthermore, a table of normal spinal cord motion values in the AP direction for each level of the cervico-thoracic-lumbar vertebral column was compiled.

Respiration was shown to have a significantly higher impact on spinal cord motion within the spinal canal when compared to the influence of heart pulsations as measured during breathholding. Next to the physiologic CSF, which circulates along the spinal canal, this respiratory-based spinal cord motion seems to be the causative factor behind the motion artifacts described in several MRI studies [13-15]. In particular, new imaging techniques such as spinal fMRI, spinal DWI or DTI could be considerably influenced by high respiration rates and high breathing depth $[4,15]$, since the measured structures are in a sub-millimeter range [5] as well as by the limited signal-to-noise ratio and spatial resolution [31].

Based on the results of our study, further studies are required to evaluate the impact of improved respiratory gating on the amount of artifacts, since most of the recent studies focus on cardiac triggering [32].

According to our results, the highest spinal cord motion values were found in the region of the cervico-thoracic junction, as well as in the region of the thoraco-lumbar junction. This finding agrees with former studies of spinal cord motion $[8,18]$ and is likely based on regional differences in CSF pulsatility that originate from the cerebral ventricles [33] and anatomical circumstances of the intumescentia cervicalis and lumbosacralis, respectively.

Previous studies have shown only minor motion of the spinal cord in left-right or right-left direction [19]. Therefore, we did not investigate this aspect of spinal cord motion in this study.

Knowledge about the considerable influence of respiration, compared to heart activity, might contribute to a reduction in motion artifacts in MRI. Attempts such as reducing the acquisition time, increasing the phase-gradient amplitude, or using interleaved multishot echo planar sequences have been undertaken [3]. In addition to the general advice that patients should not move during MRI examinations, the avoidance of deep breathing at a high respiration rate could also be recommended. Therefore, respiration-gated techniques seem to be more promising than cardiactriggering techniques. 

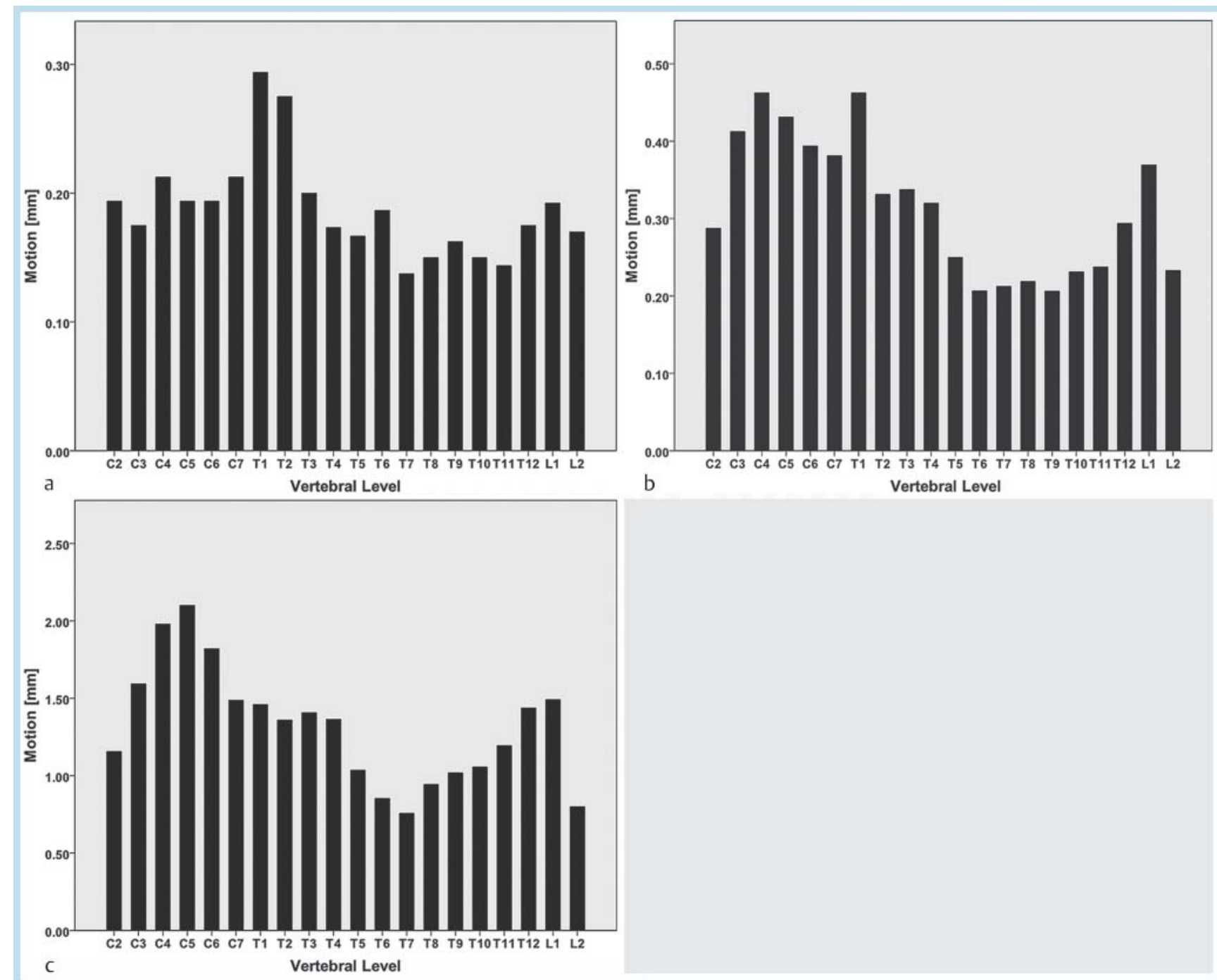

Fig. 2 a-c Spinal cord motion values in the AP direction with respect to the different breathing types at all measured levels. a Breath-holding, b normal breathing and $\mathbf{c}$ forced breathing. Peaks are visible from the middle cervical spine up to the upper thoracic levels with normal and forced breathing. A corresponding peak during breath-holding is found on the first thoracic levels. The lowest values for all breathing types are found in the mid-thoracic region.

Abb. 2 a-c Ausmaß der Rückenmarksbewegung in AP-Richtung auf den gemessenen Wirbelkörperhöhen in Abhängigkeit der unterschiedlichen Atmungstechniken. a Atemanhalten, b normale Atmung und kräftige Atmung, c die höchsten Werte bei normaler und kräftiger Atmung sind von der mittleren Halswirbelsäule bis zur oberen Brustwirbelsäule zu erkennen. Die höchsten Werte bei angehaltener Atmung sind auf Höhe der ersten Brustwirbelkörper zu finden. Die geringsten Werte wurden bei allen Atmungstechniken auf Höhe der mittleren BWS ermittelt.

\section{Limitations}

First, a relatively small number of volunteers were included. A higher number would have increased the statistical power. Second, the data were acquired from a normal healthy population, which may be different from the usual clinical population with frequent cases of age-related degenerative spinal disease. However, we tried to assess normal values in healthy subjects without any degenerative spinal cord changes. Finally, our study did not investigate inter-reader or intra-reader observer variability associated with consensus readings. However, the main spinal cord measurements were performed with the software algorithm, which permits automated measurements in a submillimeter range and should therefore not be a major source of error. Nevertheless, repeated independent readings by different readers, as well as a higher number of volunteers would be desired to proof the reliability of the applied technique in future studies.

\section{Conclusion}

$\nabla$

Normal physiological spinal cord motion values for each level of the cervico-thoraco-lumbar vertebral column were measured by MRI. Furthermore, respiration was demonstrated to be a considerable cause of motion, with a significant impact, compared to heart-related motion. This knowledge could help to reduce motion artifacts in spinal cord MRI and could suggest the use of respiration-triggering methods such as navigator echo as well-established techniques in cardiac MRI. 
Clinical Relevance of the Study

- In high-resolution or functional imaging of the spinal cord, artifact-free images are desired.

- Physiological spinal cord motion is one of the sources of motion-dependent artifacts in spine imaging.

- Respiration was demonstrated to be a considerable cause of motion, with a significant impact, compared to heart-related motion.

- This might help to reduce motion artifacts in spinal cord MRI and could suggest the use of respiration-triggering methods such as navigator echo as well-established techniques in cardiac MRI.

- In addition, a table with normal values of spinal cord motion for cervical, thoracic and lumbar levels was compiled.

\section{References}

1 Seidenwurm DJ, Wippold FJ 2nd et al. ACR Appropriateness Criteria((R)) myelopathy. Journal of the American College of Radiology: JACR 2012; 9: $315-324$

2 Haupts M, Haan J, Uhlenbrock $D$. The myelon in cervical spinal canal stenosis: imaging by X-ray and MRI. Neurosurgical review 1987; 10 : $123-125$

3 Madi S, Flanders AE, Vinitski S et al. Functional MR imaging of the human cervical spinal cord. AJNR American journal of neuroradiology 2001; $22: 1768-1774$

4 Ellingson BM, Ulmer JL, Kurpad SN et al. Diffusion tensor MR imaging of the neurologically intact human spinal cord. AJNR American journal of neuroradiology 2008; 29: 1279-1284

5 Rossi C, Boss A, Lindig TM et al. Diffusion tensor imaging of the spinal cord at 1.5 and 3.0 Tesla. RoFo: Fortschritte auf dem Gebiete der Rontgenstrahlen und der Nuklearmedizin 2007; 179: 219-224

6 Jokich PM, Rubin JM, Dohrmann GJ. Intraoperative ultrasonic evaluation of spinal cord motion. Journal of neurosurgery 1984; 60: 707-711

7 Levy LM, Di Chiro G, McCullough DC et al. Fixed spinal cord: diagnosis with MR imaging. Radiology 1988; 169: $773-778$

8 Cai J, Sheng K, Sheehan JP et al. Evaluation of thoracic spinal cord motion using dynamic MRI. Radiotherapy and oncology: journal of the European Society for Therapeutic Radiology and Oncology 2007; 84: $279-282$

9 Schaller B, Graf R. Different compartments of intracranial pressure and its relationship to cerebral blood flow. The Journal of trauma 2005; 59: $1521-1531$

10 Schroth G, Klose U. Cerebrospinal fluid flow. I. Physiology of cardiacrelated pulsation. Neuroradiology 1992; 35: 1-9

11 Greitz D, Wirestam R, Franck $A$ et al. Pulsatile brain movement and associated hydrodynamics studied by magnetic resonance phase imaging. The Monro-Kellie doctrine revisited. Neuroradiology 1992; 34: $370-380$

12 Gideon P, Thomsen C, Stahlberg $F$ et al. Cerebrospinal fluid production and dynamics in normal aging: a MRI phase-mapping study. Acta neurologica Scandinavica 1994; 89: 362 - 366

13 Kharbanda HS, Alsop DC, Anderson AW et al. Effects of cord motion on diffusion imaging of the spinal cord. Magnetic resonance in medicine: official journal of the Society of Magnetic Resonance in Medicine / Society of Magnetic Resonance in Medicine 2006; 56: 334-339
14 Brooks JC, Beckmann CF, Miller KL et al. Physiological noise modelling for spinal functional magnetic resonance imaging studies. NeuroImage 2008; 39: 680-692

15 Kong $Y$, Jenkinson $M$, Andersson $J$ et al. Assessment of physiological noise modelling methods for functional imaging of the spinal cord. NeuroImage 2012; 60: 1538 - 1549

16 Figley $C R$, Stroman PW. Development and validation of retrospective spinal cord motion time-course estimates (RESPITE) for spin-echo spinal fMRI: Improved sensitivity and specificity by means of a motion-compensating general linear model analysis. Neurolmage 2009; 44: $421-427$

17 Spuentrup E, Buecker A, Koelker C et al. Respiratory motion artifact suppression in diffusion-weighted MR imaging of the spine. European radiology 2003; 13: 330-336

18 Figley CR, Yau D, Stroman PW. Attenuation of lower-thoracic, lumbar, and sacral spinal cord motion: implications for imaging human spinal cord structure and function. AJNR American journal of neuroradiology 2008; 29: 1450 - 1454

19 Figley CR, Stroman PW. Investigation of human cervical and upper thoracic spinal cord motion: implications for imaging spinal cord structure and function. Magnetic resonance in medicine: official journal of the Society of Magnetic Resonance in Medicine / Society of Magnetic Resonance in Medicine 2007; 58: 185-189

20 Matsuzaki $H$, Wakabayashi $K$, Ishihara $K$ et al. The origin and significance of spinal cord pulsation. Spinal cord 1996; 34: 422-426

21 Mikulis DJ, Wood ML, Zerdoner OA et al. Oscillatory motion of the normal cervical spinal cord. Radiology 1994; 192: 117-121

22 Kilner PJ. Imaging congenital heart disease in adults. The British journal of radiology 2011; 84 Spec No 3: S258-S268

23 Grayburn PA, Weissman NJ, Zamorano JL. Quantitation of mitral regurgitation. Circulation 2012; 126: 2005-2017

24 Gallego J, Benammou S, Vardon G et al. Influence of thoracoabdominal pattern of breathing on respiratory resistance. Respiration physiology 1997; 108: $143-152$

25 Plathow C, Zimmermann H, Fink C et al. Influence of different breathing maneuvers on internal and external organ motion: use of fiducial markers in dynamic MRI. International journal of radiation oncology, biology, physics 2005; 62: 238-245

26 Barrett KE, Ganong WF. Ganong's review of medical physiology. 24th ed. New York London: McGraw-Hill Medical; McGraw-Hill distributor: 2012, 1 online resource (ix, 752p.)

27 Lisanti CJ, Douglas DB. Effects of breath-hold and cardiac cycle on the MRI appearance of the aorta and inferior vena cava in t2 abdominal imaging. Am J Roentgenol American journal of roentgenology 2009; 192: $1348-1358$

28 Ferrigno $M$, Hickey DD, Liner $M H$ et al. Cardiac performance in humans during breath holding. Journal of applied physiology 1986; 60: $1871-1877$

29 Canny J. A computational approach to edge detection. IEEE transactions on pattern analysis and machine intelligence 1986; 8: 679-698

30 Federal Statistic Office in Germany. Körpermaße nach Altersgruppen. Available at: https://www.destatis.de/DE/ZahlenFakten/ GesellschaftStaat/Gesundheit/GesundheitszustandRelevantesVerhalten/ Tabellen/Koerpermasse.html Accessed May 7, 2012.31.

31 Andre JB, Bammer R. Advanced diffusion-weighted magnetic resonance imaging techniques of the human spinal cord. Topics in magnetic resonance imaging: TMRI 2010; 21: 367-378

32 Rossi C, Boss A, Steidle G et al. Water diffusion anisotropy in white and gray matter of the human spinal cord. Journal of magnetic resonance imaging: JMRI 2008; 27: 476-482

33 Feinberg DA, Mark AS. Human brain motion and cerebrospinal fluid circulation demonstrated with MR velocity imaging. Radiology 1987; 163: $793-799$ 